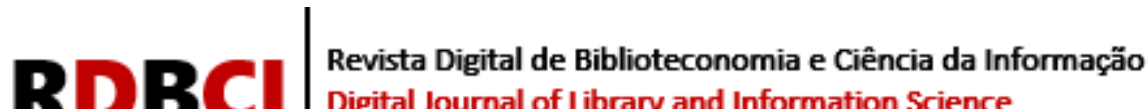 \\ Digital Journal of Library and Information Science
}

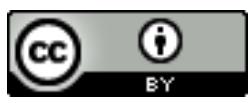

\section{A disseminação da informação científica como garantia da legitimidade dos resultados de ensaios clínicos}

\author{
Larissa Ferreira dos Angelos Cedro ${ }^{1}$ (iD https://orcid.org/0000-0001-7353-4837 \\ Claudio Gottschalg-Duque ${ }^{2}$ (iD) https://orcid.org/0000-0003-3558-466X \\ ${ }^{1}$ Universidade de Brasília, Brasília, DF, Brasil. / e-mail: larissaferreira.dac@gmail.com \\ ${ }^{2}$ Universidade de Brasília, Brasília, DF, Brasil. / e-mail: klaussherzog@ gmail.com
}

\section{RESUMO}

Este estudo tem o objetivo de identificar na literatura as publicações que retratam a necessidade de disseminação dos resultados de ensaios clínicos como critério de transparência e validação destes. Para isso, utilizou-se da técnica levantamento documental na literatura biomédica de documentos que versam sobre a transparência em resultados de ensaios clínicos. Para a busca, foram utilizados o descritor "Clinical Trial" e a palavra-chave "transparency" - ("transparency"[All Fields] AND "Clinical Trial"[All Fields]). Foi selecionada a base de dados Medical Literature Analysis and Retrievel System Online (MEDLINE) da National Libary of Medicine (NLM) dos Estados Unidos. Foram recuperados 394 documentos, retiradas possíveis duplicatas e selecionados 226 documentos de interesse para a pesquisa. De forma integrada foi estabelecida a relação da Ciência da Informação como a área que se dedica ao compartilhamento da informação através da organização, comunicação e divulgação científica.

\section{PALAVRAS-CHAVE}

Publicação. Disseminação da informação. Pesquisa médica. Confiabilidade do teste. Divulgação.

\section{The dissemination of scientific information as a guarantee of the legitimacy of the results of clinical trials}

\begin{abstract}
This study aims to identify in the literature publications that portray the need to disseminate the results of clinical trials as a criterion for their transparency and validation. For that, it was used the documentary survey technique in the biomedical literature of documents that deal with transparency in clinical trial results. For the search, the descriptor "Clinical Trial" and the keyword "transparency" - ("transparency" [All Fields] AND "Clinical Trial" [All Fields]) were used. The Medical Literature Analysis and Retrievel System Online (MEDLINE) database of the National Libary of Medicine (NLM) in the United States was selected. 394 documents were recovered, possible duplicates were removed and 226 documents of interest for the research were selected. I $n$ an integrated manner, the relationship of Information Science was established as the area that is dedicated to sharing information through the organization, communication and dissemination of science.
\end{abstract}

\section{KEYWORDS}

Publications. Information dissemination. Medical research. Test reliability. Disclosure. 


\section{RDBCI}

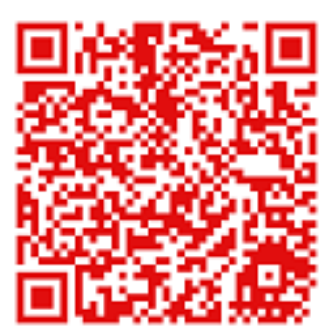

JITA: BG. Information dissemination and diffusion. 


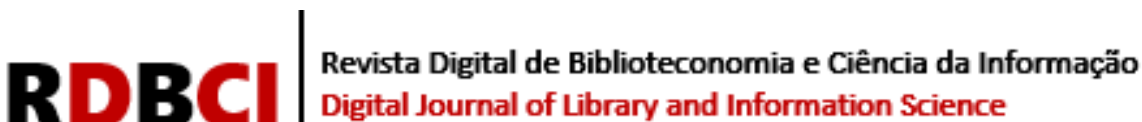

\section{INTRODUÇÃO}

A necessidade de organizar, armazenar e disponibilizar a informação após a 'explosão informacional' no pós-guerra fez emergir uma nova área do conhecimento, a Ciência da Informação (CI). Essa ciência, desde sua origem, teve como preocupação o acesso à informação, apresentando seus problemas entrelaçados com o processo de comunicação tal como descrito, em 1949, por Shannon e Weaver (emissor, mensagem/ canal e receptor).

Em meados da década de 70, era amplamente reconhecido que a base da CI dizia a respeito aos processos de comunicação humana (isto é, um aprofundamento da definição proposta por BUSH), ou como Belkin e Robertson (1976) resumiram: 'o propósito da CI é facilitar a comunicação de informações entre seres humanos'. (SARACEVIC, 1996, p. 47).

Para definir a Ciência da Informação, Saracevic (1995, p. 2) ainda afirma que este campo se detém à problemática da comunicação dos conhecimentos na sociedade no contexto das necessidades informacionais individuais ou coletivas. Na mesma linha, Yeps (2010, p. 105) afirma que a CI "tiene como objeto de estudio un peculiar proceso de información compuesto de sujetos emisores, mensaje, medio y sujeto receptor".

Observa-se que desde o século XVIII, e principalmente o século XIX, efeitos da industrialização de produtos e crescente desenvolvimento tecnológico na Europa já se apresentavam como um exponente fator de crescimento intelectual. Como resultado, houve sucessivos e numerosos inventos e, por consequência, a inevitável aglomeração de registros sobre avanços e descobertas científicas.

Neste mesmo sentido, Oliveira (2006, p. 25) aponta que, após as mudanças do Renascimento, "o século 19 teve o privilégio de observar a eclosão de nova era na medicina com base no experimento e na terapêutica. Passava-se à era da crítica científica e da verificação sistemática da segurança e eficácia dos remédios".

Assim, a pesquisa terapêutica se desenvolveu demasiadamente e, por possuir uma diversidade de objetivos, os resultados dessas pesquisas passaram a se apresentar em diversos formatos, entre eles os estudos clínicos com seres humanos (ensaios clínicos).

A comunicação científica alcançada na publicização dos ensaios clínicos fornece àqueles que necessitam da informação - sejam eles pacientes, profissionais, pesquisadores, financiadores e demais interessados - registros públicos e atualizados sobre os estudos, eventos adversos e os resultados encontrados.

No entanto, embora esses ensaios tenham produzido avanços, sofrido regulações e melhorado ao longo do tempo, ainda há grandes desafios a serem encarados que limitam a completa transparência dos dados de ensaios clínicos: como o viés de seleção de voluntários, o viés de hipótese e o viés de publicação.

Esse artigo tem como objetivo realizar uma revisão sistematizada da literatura biomédica para compreender como a prática da disseminação da informação pode auxiliar a transparência dos ensaios clínicos.

\section{CIÊNCIA DA INFORMAÇÃO E A DISSEMINAÇÃO DA INFORMAÇÃO}

Tendo em vista que em todos os períodos da história da humanidade houve descobertas, em maior e menor grau, e que de alguma forma essas foram registradas, Fontoura 


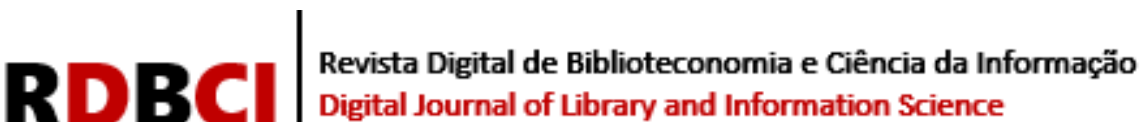

(2012, p. 89) afirma que "descobrir uma forma de coordenar todas as informações sobre algo foi o foco principal de Paul Otlet, e ele se propôs a isso ciente das vantagens da existência de um sistema ou método que permitisse que isto fosse atingido de forma prática e coordenada".

Paul Marie Ghislain Otlet, advogado Belga, nascido em Bruxelas em 1868, hoje, é considerado o pai da Documentação. Desde seu estágio em um escritório de Direito, Paul Otlet se envolveu com publicações científicas da área jurídica. Seu foco principal foi montar um repertório universal em que todas as publicações pudessem ser organizadas e recuperadas a todos que tivessem interesse. Com seus ideais positivistas, Otlet acreditava também que poderia aplicar nas Ciências Sociais regras e procedimentos que já tivessem sido aplicados com sucesso nas Ciências Naturais.

No escritório de Picard, professor de Otlet, ele pôde conhecer Henri La Fontaine, advogado e político, com quem, em 1893, cria o Instituto Internacional de Bibliografia Sociológica (International Institute of Sociological Bibliography - IISB). Esse instituto representa a concepção do pensamento otleano, compartilhado com La Fontaine, sobre a organização lógica e racional do trabalho científico. (LÓPEZ-YEPS, 1995, p. 62).

Além desse aspecto, os dois advogados se identificavam com ações pacifistas e defendiam a tese de que tratar a informação era um ato político e de redução das desigualdades sociais. Nessa perspectiva, Otlet e La Fontaine tomam como tarefa a organização e publicação de bibliografias especializadas nas áreas de Direito, Psicologia e Sociologia. Para Otlet, "elas [bibliografias] se constituem na fonte de informações relativas aos livros existentes e na base de toda a documentação. Elas são os intermediários entre os livros e os leitores" (OTLET, 1934, p. 286).

A visão Paul Otlet e Henri La Fontaine é sintetizada na máxima organização e disseminação da informação registrada. Essa perspectiva revela a necessidade já reconhecida por eles de que o acesso à informação é indispensável para o progresso da sociedade. Fontoura, estudioso da obra de Otlet, afirma que ele:

em 1892 escreveu um artigo para o jornal Palais do "Cercle du Jeune Barreau de Bruxelles" intitulado "Un Peau de Bibliographie" no qual tece considerações sobre as imensas possibilidades de avanço científico, caso fosse possível obter-se maior organização do conhecimento humano registrado (FONTOURA, 2012, p. 132).

A falta de organização da informação, entendida aqui como a falta dos sistemas que facilitam o controle, o ordenamento e o agrupamento da informação, e ainda o difícil acesso às informações trazem ao pesquisador complexidade no processo de pesquisa e produção de conhecimento. E podem causar transtornos e retardos no trabalho e até tornar seus resultados inviáveis.

Em tempos de avanço exponencial e repentino das tecnologias de informação e do advento da $w e b$, tem-se potencializada essa necessidade de compartilhamento, interatividade e criação de informações, possibilitando o indivíduo ser, além de receptor, o gerador de informações.

Diante de tanta informação disponível, torna-se cada vez mais difícil a recuperação precisa e coerente de informações desejáveis. Ao mesmo tempo, tem-se a impressão de que, em todas as áreas do conhecimento, muitas informações não são acessadas.

Levando em consideração que os processos de comunicação foram desde o início uma preocupação da Ciência da Informação e, como José López-Yepes (2010) afirma que ela é uma disciplina geral para serviço de todo o conhecimento, ou seja, um tipo de ciência para ciência, é possível afirmar a relação da CI nos métodos comunicativos de todas as ciências. 


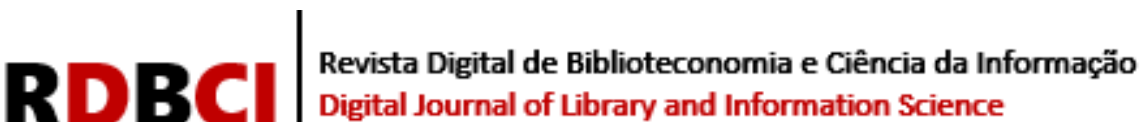

Neste sentido, na área das Ciências da Saúde, mais especificamente em estudos clínicos, cada vez mais, tem-se observada a necessidade da disseminação e do compartilhamento da informação de procedimentos e resultados dos ensaios clínicos. Isso se deve pela compreensão de que a publicidade desses registros torna a investigação mais transparente e, por consequência, mais ética.

$\mathrm{Na}$ literatura, o processo de compartilhamento de informação entre os pares é denominado de comunicação científica. De acordo com Caribé (2015, p. 90), é atribuída a John Desmond Bernal a responsabilidade do termo comunicação científica, descrito no capítulo Comunicação científica do livro A função Social da Ciência (1939).

Observa-se que, historicamente, desde o século XV, a troca de cartas e documentos com menor critério de formalidade era o mecanismo de comunicação entre os pesquisadores. Com a invenção da imprensa na Europa, por volta do início do século XVI, a distribuição de livros científicos facilitou o compartilhamento dos estudos científicos. Mas somente nos séculos XVII e XVIII foi que a comunicação da ciência tomou maiores proporções.

Valeiro e Pinheiro (2008, p. 161) apontam, no livro Communication: the essence of Science (1979), que Garvey e Griffith definem a comunicação científica "como o conjunto de atividades associadas à produção, à disseminação e ao uso da informação". Ou seja, esses autores entendem que a comunicação científica se inicia antes do ato de difundir a informação para uma comunidade, mas principia nos primeiros momentos da investigação científica e se estende até o uso dessa pelos seus receptores.

O conhecimento científico, então, é o resultado da pesquisa, da produção e da comunicação. E é por meio desse último aspecto que se pode submeter ao exame crítico e aos testes realizados por outros cientistas a fim de validar aquele conhecimento como verdadeiro e útil.

Mueller e Passos (2000, p. 14) ressaltam que "se um cientista aceita uma teoria é porque admite que ela pode explicar um fenômeno ou permite fazer predições sobre o comportamento desse fenômeno". Assim, a aprovação de outros cientistas confere ao conteúdo do documento o aval de 'conhecimento científico'.

Tal comunicação possibilita expansão do estudo, novas oportunidades, possíveis trocas de conhecimento e avanços práticos, bem como assegura a não duplicidade de investigação e, com isso, dispêndios de recursos humanos e financeiros em pesquisas já realizadas.

\subsection{Divulgação Científica}

Neste contexto de democratização do conhecimento também está a divulgação científica - termo que busca refletir a tradução do conhecimento científico em termos e conceitos de fácil compreensão aos não cientistas. Esse processo vislumbra o resumo e as práticas didáticas de compartilhar um determinado conteúdo, outrora escrito em linguagem reconhecida por poucos, para um determinado grupo social com uma linguagem mais acessível.

O conhecimento científico é parte integrante da cidadania plena e do processo de inclusão social, uma vez que possibilita ao indivíduo ter acesso às informações mínimas imprescindíveis a uma cidadania ativa e transformadora. Por outro lado, a democracia não se resume à distribuição do saber, embora seja essencial para sua constituição (CALDAS, 2010, p. 39).

Nessa orientação, a divulgação científica tem funções ora educacionais, ora culturais, políticas e ideológicas (ALBAGLI, 1996, p. 397). Isso se deve pelos resultados pretendidos quando há um esforço no compartilhamento e contextualização da informação científica. 


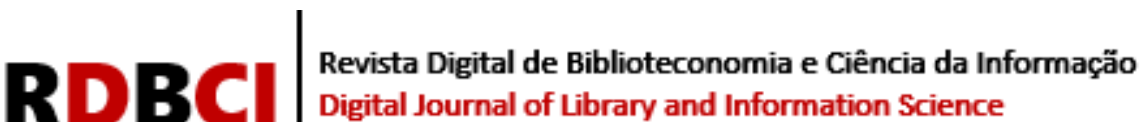

Pensando na função educacional, a divulgação científica presta o papel de fornecer à sociedade uma visão crítica dos benefícios, ou até mesmo dos malefícios, da produção científica. Quanto à cultural, a transmissão de informação científica gera nos indivíduos uma proximidade curiosa que os faz estabelecer um padrão de constante busca do conhecimento para seus problemas diários.

\begin{abstract}
Essa crescente inserção sócio-econômica da ciência supõe, por sua vez, a aceitação, pela sociedade, do caráter benéfico da atividade científica e de suas aplicações. Do mesmo modo, implica uma rápida assimilação, na vida cotidiana dos indivíduos, dos artefatos técnico-científicos transformados em objetos de consumo, dada a velocidade com que vêm ocorrendo as inovações nesse campo. A própria sociedade amplia seu interesse e preocupação em melhor conhecer - e também controlar - o que se faz em ciência e o que dela resulta (ALBAGLI,1996, p. 396)
\end{abstract}

Os resultados políticos e ideológicos alcançados com a divulgação científica refletem diretamente o posicionamento cívico do cidadão, particularmente nos assuntos caros à ciência. Quando bem informados, os indivíduos conseguem melhor opinar na escolha de políticas públicas prioritárias e nas tomadas de decisões do governo.

Inúmeras são as vantagens da popularização da ciência, ainda mais se acrescentado o fator tecnológico que coopera para agilidade e massificação da divulgação científica. Valeiro e Pinheiro defendem a hipótese de que a comunicação e a divulgação científica estão cada vez mais se aproximando por meio das Tecnologias de Informação e Comunicação (TICs). Para elas, o público-alvo "[...] é percebido com novas dimensões, conformando-se ou formando-se em novos contornos, proporcionado das TICs que permitem percorrer, em fração de segundos, distâncias jamais imaginadas até bem recentemente" (VALEIRO; PINHEIRO, 2008, p. 167).

\subsection{Ensaios Clínicos e a Comunicação Científica}

O ensaio clínico é um instrumento que relata de maneira detalhada pesquisas biomédicas que buscam conhecer "desde a potencial aplicação humana de novos achados laboratoriais até a geração de evidências robustas sobre tratamentos ou intervenções preventivas no atendimento" (HUDSON; LAUER; COLLINS, 2016, p.1353).

A pesquisa clínica envolvendo seres humanos apresenta incontestáveis benefícios no progresso científico. No entanto, ao longo dos séculos, a prática demonstrou abertura para experimentações sem critérios, com objetivos ilegítimos e até mesmo abusivos e antiéticos.

Em 1947, em decorrência do julgamento de médicos envolvidos em experimentos abusivos realizados durante a Segunda Guerra Mundial, foi elaborado o primeiro documento internacional (Código de Nuremberg) que orientava os aspectos éticos das pesquisas com seres humanos. Reconhecendo algumas falhas desse código, em 1964, a Associação Médica Mundial elaborou a Declaração de Helsinque, durante a $18^{a}$ Assembleia Médica Mundial.

Levando em consideração o Código de Nuremberg, a Declaração de Helsinque e outros documentos internacionais que emanaram declarações e diretrizes para pesquisas que envolvem seres humanos, no Brasil, o Conselho Nacional de Saúde, do Ministério da Saúde, aprovou a Resolução n 196 em 10 DE OUTUBRO DE 1996, que "configurou-se como o primeiro marco nacional para a regulamentação de pesquisas envolvendo seres humanos" (LORDELLO; SILVA, 2017, p. 8)

Essa resolução foi atualizada pela Resolução ${ }^{\circ} 466$, de 12 de dezembro de 2012, inspirada pelos princípios bioéticos da beneficência, da não-maleficência, da autonomia e demais outros. Por meio dela, diretrizes e normas regulamentadoras para pesquisas envolvendo 


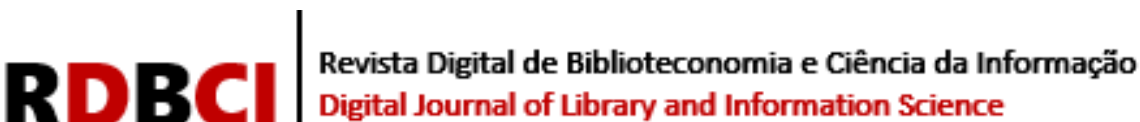

seres humanos foram tratadas, bem como a recomendação da submissão de todo projeto de pesquisa envolvendo seres humanos a uma revisão ética pelo Sistema CEP/CONEP.

No entanto, algumas críticas foram feitas pelos pesquisadores de Ciências Humanas e Sociais, denominando de "imperialismo bioético o movimento de as ciências biomédicas exigirem que as investigações das ciências humanas e sociais fossem conduzidas de acordo com seus critérios" (LORDELLO; SILVA, 2017, p. 8), demonstrado até mesmo na formação acadêmica dos participantes do Sistema CEP/CONEP.

Diante da situação, em 7 de abril de 2016, o Conselho Nacional de Saúde aprovou a Resolução $n^{\circ}$ 510, que leva em consideração o aspecto ético como "uma construção humana, portanto histórica, social e cultural" (BRASIL, 2016), o qual assume o caráter pluralista e específico das Ciências Humanas e Sociais.

Durante duas décadas de atualizações, cabe ressaltar que as resoluções de 2012 e de 2016 levam em consideração a disponibilização de resultados da pesquisa em formato de relatório final para os pacientes envolvidos e para o Sistema CEP/CONEP. Mas somente a resolução $n^{\circ} 466 / 12$ responsabiliza o pesquisador a "encaminhar os resultados da pesquisa para publicação, com os devidos créditos aos pesquisadores associados e ao pessoal técnico integrante do projeto." (BRASIL, 2012).

Ressalta-se que a Declaração de Helsinque, que teve sete revisões entre os anos de 1975 a 2013, destaca a necessidade de registro de pesquisa e disseminação dos resultados que contribuem para reger os aspectos éticos nas investigações clínicas em seres humanos. Salientase na Declaração alguns artigos que revela a importância do registro, da disponibilização e da comunicação científica dos protocolos de pesquisa.

O artigo 17 da Declaração impõe o registro e o acompanhamento dos possíveis riscos na pesquisa médica. $\mathrm{O}$ artigo 22 determina a descrição e a justificação do desenho e o desempenho em um protocolo de pesquisa que contenha as principais informações da pesquisa clínica. E os artigos 35 e 36 retratam a necessidade de publicação.

35. Todo o ensaio clínico deve ser registado numa base de dados com acesso público
antes de se iniciar o recrutamento do primeiro participante.
36. Os investigadores, autores, promotores, revisores e editores têm, todos, obrigações
éticas quanto à publicação e disseminação dos resultados da investigação. Os
investigadores têm o dever de colocar os resultados das suas investigações em seres
humanos publicamente acessíveis e são responsáveis pela exatidão e pela
completitude dos seus relatórios. Todos devem acatar normas de orientação em vigor
sobre relatórios éticos. Devem ser publicados, ou pelo menos tornados publicamente
disponíveis, não só os resultados positivos, mas também os negativos ou
inconclusivos. As fontes de financiamento, as ligações institucionais e os conflitos de
interesse devem ser declarados quando da publicação. Os relatórios da investigação
que não estejam conformes com os princípios desta Declaração não devem ser aceites
para publicação (WMA, 2013).

Contudo, diante desses e outros esforços, ainda é verificado que a divulgação de resultados de pesquisas clínicas não é completamente confiável. Muitas vezes, é influenciada por interesses comerciais. Em experimentos com seres humanos, a comunicação e a divulgação científica são essenciais para gerar confiança e credibilidade, além de evitar a exposição de pacientes a intervenções já estudadas e que tiveram os resultados conhecidamente ineficazes.

A partir de uma revisão sistematizada, este artigo busca compreender o estado da arte das avaliações de transparência dos ensaios clínicos, o valor da disseminação da informação, e elencar, de forma sistemática, categorias para agrupar os documentos recuperados. 


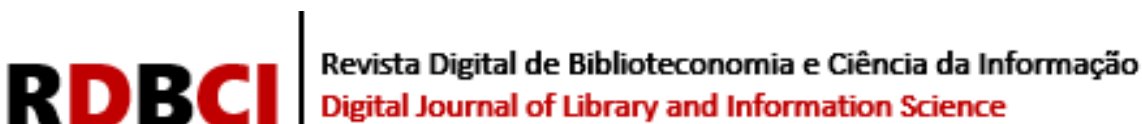

\section{PROCEDIMENTOS METODOLÓGICOS}

Os procedimentos metodológicos deste estudo foram empreendidos a partir de pesquisa bibliográfica para a fundamentação teórica do estudo, seguida de levantamento documental na literatura biomédica de documentos que retratassem a avaliação de publicação e transparência em resultados de ensaios clínicos.

Optou-se em selecionar artigos, relatórios e editoriais científicos que são avaliados por pares, situação não presente em outras modalidades de divulgação científica. Utilizou-se o filtro de "full text" - texto completo - para garantir o acesso integral aos documentos recuperados. O período delimitado para esta pesquisa é de 6 (seis) anos (2014-2019). Esta escolha tomou como base o ano da última revisão da Declaração de Helsinque (2013) em que ressaltou as "obrigações éticas quanto à publicação e disseminação dos resultados da investigação [dos ensaios clínicos]" (WMA, 2013), como já discutido neste trabalho.

Para a busca, foi selecionada a base de dados Medical Literature Analysis and Retrievel System Online (MEDLINE) da National Libary of Medicine (NLM) dos Estados Unidos. Essa base de dados foi escolhida para o estudo devida sua representação literária internacional na área da biomedicina, nela são indexados aproximadamente 5.400 periódicos dos Estados Unidos e de mais 80 países.

No dia 5 de julho de 2019, foi aplicada a estratégia de busca: ("Clinical Trial" AND "transparency") - e recuperados 394 registros, nos idiomas inglês, português e espanhol. Foi realizada a leitura de título e resumo para selecionar as publicações que identificavam a relevância da transparência na eficiência, na qualidade e na ética das publicações de ensaios clínicos.

Concluídas as etapas de seleção e leitura dos títulos e resumos, encontrou-se uma amostra de 226 artigos que foram lidos para preenchimento da ficha de análise e assim agrupados em categorias. Grant e Booth (2009, p.103) identificam esse processo de "incluir um ou mais elementos do processo de revisão sistemática" com flexibilização nos aspectos de busca e avaliação como uma por Revisão Sistematizada da Literatura.

Assim como na Revisão Sistemática, a Revisão Sistematizada exige uma construção pré-definida de critérios de seleção, avaliação e codificação dos resultados levantados, que são modelados em uma pequena amostra de documentos elegíveis.

\section{ANÁLISE E DISCUSSÃO DOS RESULTADOS}

Foram recuperados 394 artigos e, descartadas as possíveis duplicatas, obteve-se uma amostra inicial de 386 documentos (tabela 1). Desses, 58,55\% estão relacionados com a discussão entre a necessidade de transparência e a divulgação de resultados de ensaios clínicos (tabela 2). Já os outros documentos descartados da análise estavam relacionados por tratarem de ensaios com produtos transparentes, por exigirem orçamento transparente, por aplicarem a transparência nas práticas diretas com pacientes ou por terem a palavra transparência no documento com outros sentidos diferentes ao buscado nessa pesquisa.

Tabela 1. Resultado da busca na base PubMEd

Recuperados
Duplicados
Total 


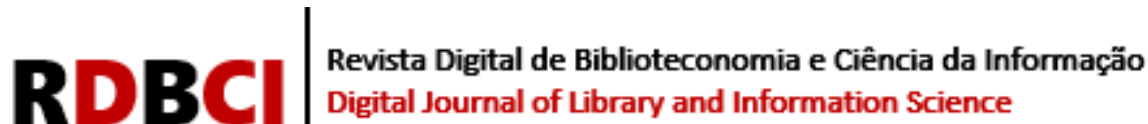

394

8
386

Fonte: os autores

Tabela 2. Resultado da análise da busca

\begin{tabular}{|c|c|c|}
\hline Total recuperados & Selecionados & Percentil \\
\hline 386 & 226 & $58,54 \%$ \\
\hline
\end{tabular}

Fonte: os autores

Foi observada uma tendência de aumento de publicação de artigos com a temática selecionada através da estratégia de busca. Ressalta-se que a pesquisa foi realizada no meio do ano de 2019 e, por isso, a quantidade recuperada neste ano é menor a que o ano anterior. Acrescentando ainda que dependendo dos prazos de processamento das revistas, um artigo publicado pode demorar meses para ser recuperado em uma base de dados (gráfico 1).

Gráfico 1. Quantidade de artigos recuperados por ano.

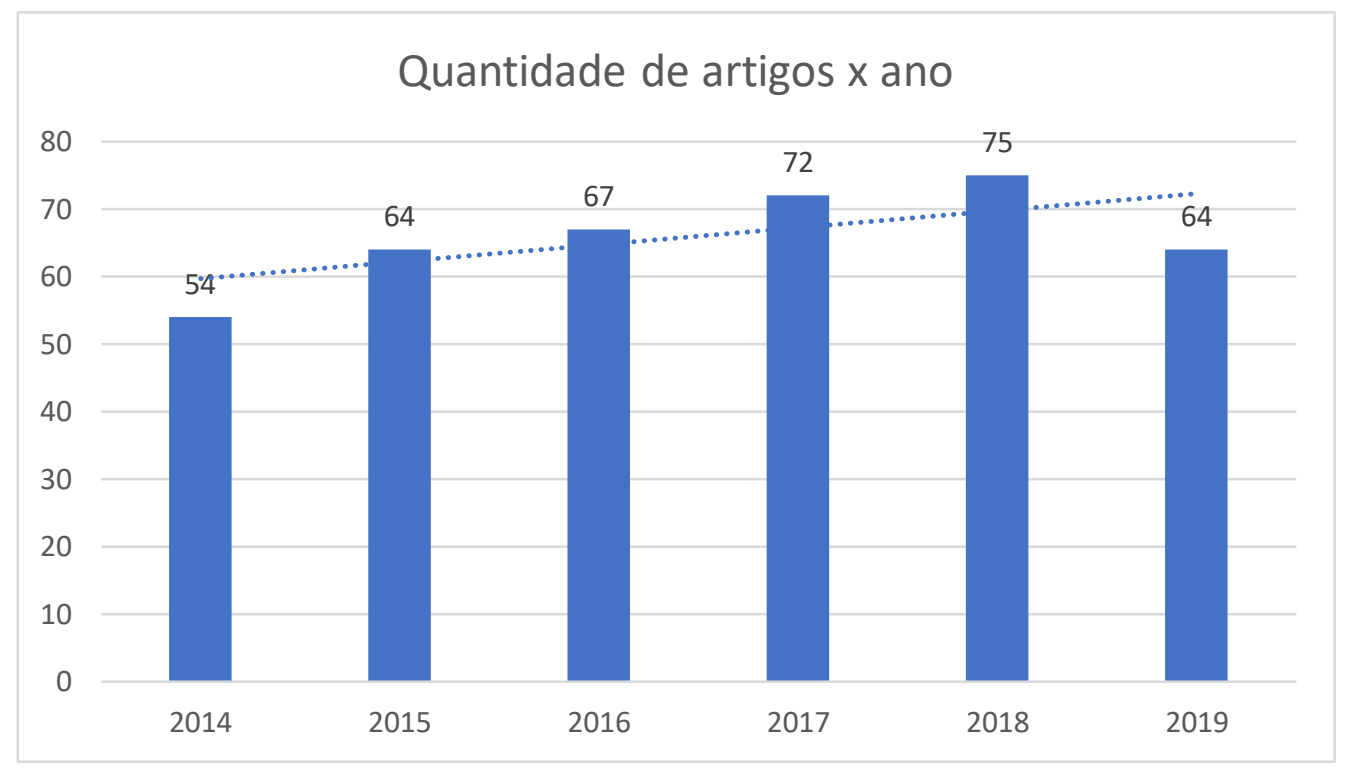

A partir do preenchimento da ficha de análise, pode-se organizar os artigos recuperados em cinco categorias: a) sugestão de mudanças nos protocolos, ou seja, revisão de práticas atual de registro inicial e final; b) participação mais ativa dos pacientes envolvidos, incluindo relatos de sucesso com a divulgação científica; c) controle de dados, que compreende a observação de dados ausentes nas registros de ensaios, os empecilhos para reutilização de dados e a ética nos relatórios; d) vieses, tais como de publicação, de seleção, de interesses e de relato; e e) necessidade de transparência nos processos de ensaios clínicos, que abrange a importância do acesso aberto, a adesão de tecnologias e a transparência de contratos.

Entre os documentos selecionados, observa-se maior discussão ética e de protocolos em ensaios clínicos praticados em países como Estados Unidos, México, França, China e Estônia. No Brasil e na Índia também houve publicações que analisavam o processo de ensaios clínicos, principalmente, como relata Petryna, o baixo custo da pesquisa e a fragilidade do 


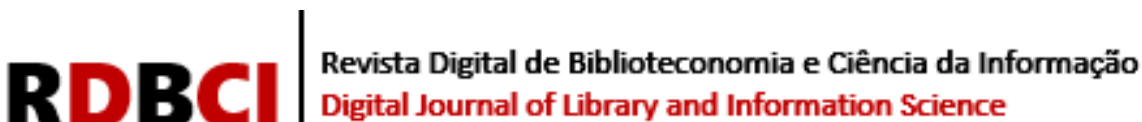

sistema de saúde atraem a indústria de ensaios clínicos "dando legitimidade à experimentação que, em outras circunstâncias, seria negada" (PETRYNA, 2011, p. 131).

Ressalta-se que, entre todos os artigos categorizados em mudanças de protocolos, foram encontradas discussões de como têm sido praticados o registro e a publicização dos resultados. De alguma forma, todos os documentos selecionados criticam o instrumento metodológico dos ensaios. Isso se deve, segundo os autores, pelas possíveis brechas para viés de publicação ou pelo 'embelezamento' dos resultados encontrados.

Um dos artigos selecionado na categoria de participação ativa dos pacientes, dos autores Yusuf Yazic e Hasan Yazic, destaca a função do Termo de Consentimento Informado que "deve ser também a principal fonte de informação do público sobre as razões do estudo planejado, o que é conhecido no campo sobre o estudo proposto e o que esperar em relação à eficácia e ao dano" (YAZICI, Y; YAZICI, H, 2010, p. 121, tradução nossa).

Esses autores apontam que o documento que registra o consentimento dos pacientes deve permanecer público e ser submetido ao Institucional Review Board (Conselho de Revisão Institucional). Eles defendem que além do registro inicial, os ensaios devam ser publicados para que qualquer "pessoa interessada possa ter acesso total ao modo de conduta dos testes antes, durante ou depois de ser conduzido, [...] tornando padrões éticos mais elevados" (YAZICI, Y; YAZICI, H, 2010, p. 121, tradução nossa).

É pontuado nos diversos artigos que a transparência dos ensaios clínicos é um padrão desejado para o desenvolvimento da área e conduz a diversas vantagens. Diante das categorias encontradas, percebe-se que ainda existem critérios a serem seguidos e aperfeiçoados, dentre eles a disseminação correta, segura e completa da informação.

Entre os artigos elencados na categoria de 'necessidade de transparência nos processos de ensaios clínicos', destacamos um estudo publicado no Journal of Clinical Epidemiology que analisa 2.132 relatórios de resultados de ensaios clínicos produzidos nos Centros Médicos Universitários da Alemanha, entre 2009 e 2013. Os autores afirmam que "Os resultados de ensaios clínicos constroem a espinha dorsal da medicina baseada em evidências [...]. A não divulgação ou disseminação atrasada dos resultados dos testes afeta negativamente todos esses processos de tomada de decisão" (2019, tradução nossa). E concluem: "ainda existe um forte atraso ou mesmo ausência de divulgação de resultados em muitos ensaios". (WIESCHOWSKI; RIEDEL; WOLLMANN, et al., 2019, tradução nossa)

Por fim, pontuamos o relatório publicado no Expert Review of Clinical Pharmacology, que também foi agrupado na categoria de 'necessidade de transparência nos processos de ensaios clínicos', o qual identifica quais ensaios clínicos, nos últimos três anos, foram traduzidos para uma linguagem adequada ao público. O relatório adverte que "a divulgação oportuna e eficaz dos resultados dos ensaios clínicos não é apenas essencial para o desenvolvimento, diagnóstico e tratamento de condições médicas, mas também cumpre uma obrigação ética de informar os pacientes e o público" (GETZ, K; FARIDES-MITCHELL, J, 2019, tradução nossa).

Os resultados encontrados nos documentos recuperados reforçam a afirmação já citada de Valeiro e Pinheiro de que a comunicação e a divulgação científica estão cada vez mais se aproximando. Em vários artigos, é mencionada a importância do compartilhamento de informações dos ensaios tanto para os pares quanto para a sociedade, principalmente para aquela envolvida na pesquisa clínica. 


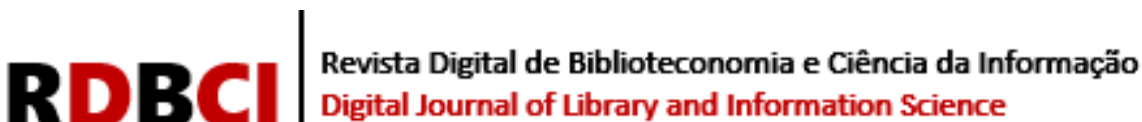

\section{CONSIDERAÇÕES FINAIS}

A Ciência da Informação, conhecida como a ciência das ciências desde seu nascimento, tem-se preocupado com a problemática da organização e disseminação da informação. Para o progresso científico em todas as áreas, é requerida a disseminação da informação sem fronteiras.

Em relação aos avanços nas investigações das Ciências da Saúde, o desenvolvimento de ensaios clínicos confiáveis é o padrão-ouro exigido para a construção do conhecimento científico. Para tal efeito, a comunicação e divulgação científicas são responsáveis pela caracterização da qualidade científica. No entanto, nos últimos anos, observou-se que esse paradigma tem se diluído em baixos níveis de transparência, relatórios seletivos e influência de financiadores aos resultados publicados.

Diante de um levantamento bibliográfico na literatura biomédica, foram selecionados 226 (duzentos e vinte seis) artigos científicos que relatavam o comportamento científico falho quanto à qualidade de transparência, ausência de dados, vieses e conflitos de interesses.

Levando em consideração que a Declaração de Helsinque fomentou o dever ético dos envolvidos na disseminação pública dos resultados das pesquisas com seres humanos, foi observada uma crescente valorização da comunicação científica ao longo dos últimos 6 (seis) anos.

A despeito disso, a análise desses documentos aponta que a qualidade dos ensaios clínicos está intimamente relacionada à qualidade dos dados disponíveis, o que torna um ciclo retroalimentado, ou seja, um estudo clínico de qualidade depende de outros resultados de qualidade já produzidos. O contrário pode fornecer um retrato parcial ou impreciso dos resultados.

Com o crescimento exponencial das informações disponíveis, compartilhar dados não é uma tarefa simples, pois exige organização e métodos. Porém, é uma prática que pode ser auxiliada pela Ciência da Informação e que permite legitimar a produção científica por meio de exame crítico realizado por outros cientistas a fim de validar tais dados como verdadeiros e úteis.

\section{REFERÊNCIAS}

ALBAGLI, Sarita. Divulgação científica: Informação científica para cidadania. Ciência da Informação, Brasília, v. 25, n. 3, dec. 1996. Disponível em:

http://revista.ibict.br/ciinf/article/view/639. Acesso em: 17 jun 2019.

BRASIL. Ministério da Saúde. Conselho Nacional em Saúde. Resolução nº466, de 12 de dezembro de 2012. Disponível em:

https://bvsms.saude.gov.br/bvs/saudelegis/cns/2013/res0466_12_12_2012.html. Acesso em: 2 abril 2020.

BRASIL. Ministério da Saúde. Conselho Nacional em Saúde. Resolução n 510, de 7 de abril de 2016. Disponível em:

http://bvsms.saude.gov.br/bvs/saudelegis/cns/2016/res0510 0704 2016.html. Acesso em: 2 abr. 2020. 


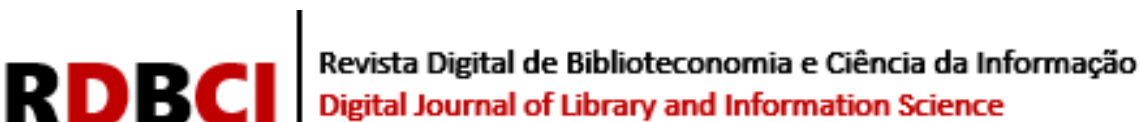

BUSH, Vannevar. As We May Think. The Atlantic. s.n, July 1945. 8p. Disponível em: https://www.theatlantic.com/magazine/archive/1945/07/as-we-may-think/303881/. Acesso em: 7 jun. 2019.

CALDAS, Graça. Divulgaçao científica e relações de poder. Informação \& Informação, [online], v. 15, n. 1esp, p. 31-42, dez. 2010. Disponível em:

http://www.uel.br/revistas/uel/index.php/informacao/article/view/5583. Acesso em: 10 jun. 2019. doi:http://dx.doi.org/10.5433/1981-8920.2010v15n1espp31.

CARIBÉ, Rita de Cássia do Vale. Informação \& Sociedade: Estudos, Paraíba, n. 3, v. 25, p. 89-104, 2015. Disponível em: http://www.brapci.inf.br/index.php/res/v/93078. Acesso em: 20 jun 2019.

FONTOURA, Marcelo Carneiro da. A documentação de Paul Otlet: uma proposta para a organização racional da produção intelectual do homem. 2012. 219 f., il. Dissertação (Mestrado em Ciência da Informação) - Universidade de Brasília, Brasília, 2012.

GETZ, K; FARIDES-MITCHELL, J. Assessing the adoption of clinical trial results summary disclosure to patients and the public. Expert Rev Clin Pharmacol. 2019, n. 12, v. 7, p. 573 578. doi:10.1080/17512433.2019.1615441. Disponível em:

https://pubmed.ncbi.nlm.nih.gov/31050914/. Acesso em: 03 ago. 2019.

GRANT, M. J.; BOOTH, A. A typology of reviews: an analysis of 14 review types and associated methodologies. Health Information \& Libraries Journal, v.26, n.2, p. 91- 108. 2009. Disponível em: <https://doi.org/10.1111/j.1471-1842.2009.00848>. Acesso em: 30 maio 2019.

HUDSON, Kathy L.; LAUER, Michael S.; COLLINS, Francis S. Toward a New Era of Trust and Transparency in Clinical Trials. JAMA, [online], v. 316, n.13, p. 1353-1354. 2016. doi:10.1001/jama.2016.14668

LOPÉZ-YEPES, José. La documentación como disciplina: teoria e historia. Pamplona: Ediciones Universidad de Navarra. 2. ed. atu. y ampl., 1995.

LOPÉZ-YEPES, José. Aportaciones a una investigación teórica en el ámbito de la comunicación: ¿qué es Bibliotecología/Documentación/Ciencia de la Información?. Perú, Revista de comunicación, n. 9, 2010, p. 95-110. Disponível em: https://dialnet.unirioja.es/servlet/articulo?codigo=3395386. Acesso em: 4 jul. 2019.

LORDELLO, Silvia Renata; SILVA, Isabela Machado da. Resolução nº 510/2016 do Conselho Nacional de Saúde: um panorama geral. Rev. SPAGESP, Ribeirão Preto, v. 18, n. 2, p. 06-15, 2017. Disponível em:

http://pepsic.bvsalud.org/scielo.php?script=sci_arttext\&pid=S167729702017000200002\&lng=pt\&nrm=iso. Acesso em: 4 abr. 2020.

MUELLER, Suzana P. M.; PASSOS, Edilenice J. L. As questões da comunicação científica e a ciência da informação. In: MUELLER, Suzana P. M.; PASSOS, Edilenice J. L. (Org.). Comunicação científica. Brasília: Ciência da Informação, 2000. p. 13-22. Disponível em: http://repositorio.unb.br/handle/10482/1444. Acesso em: 5 jun 2019. 


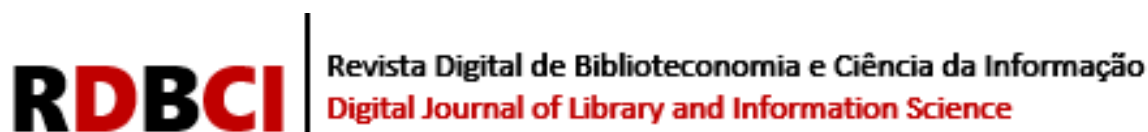

OLIVEIRA, Granville Garcia de. Ensaios clínicos: princípios e práticas. Brasília: Ministério da Saúde. Agência Nacional de Vigilância Sanitária. 2016. 328 p.

OTLET, Paul. Traité de Documentation: le livre sur le livre: théorie et patique. Bruxeles: Editiones Mundaneum. 1934. Disponível em: http://lib.ugent.be/fulltxt/handle/1854/5612/Traite de documentation ocr.pdf. Acesso em: 11 jun 2019.

PETRYNA, Adriana. Experimentalidade: ciência, capital e poder no mundo dos ensaios clínicos. Horiz. antropol., Porto Alegre, v. 17, n. 35, p. 127-160, Jun 2011. Disponível em: http://www.scielo.br/scielo.php?script=sci_arttext\&pid=S010471832011000100005\&lng=en\&nrm=iso. Acesso em: 20 jun 2019.

SARACEVIC, Tefko. A natureza interdisciplinar da ciência da informação. Ciência da Informação, Brasília, v. 24, n. 1, abr. 1995. Disponível em: http://revista.ibict.br/ciinf/article/view/608. Acesso em: 5 jun 2019.

SARACEVIC, Tefko; , . Ciência da informação: origem, evolução e relações. Perspectivas em Ciência da Informação, Belo Horizonte, v. 1, n. 1, mar. 2008. Disponível em: http://portaldeperiodicos.eci.ufmg.br/index.php/pci/article/view/235. Acesso em: 15 jun. 2019. doi:http://dx.doi.org/10.1590/1981-5344

VALEIRO, Palmira Moriconi; PINHEIRO, Lena Vania Ribeiro. Da comunicação científica à divulgação. Transinformação, Campinas, v. 20, n. 2, p. 159-169, 2008.

http://dx.doi.org/10.1590/S0103-37862008000200004.

WIESCHOWSKI S, RIEDEL N, WOLLMANN K, et al. Result dissemination from clinical trials conducted at German university medical centers was delayed and incomplete. J Clin Epidemiol. 2019, n. 115, p. 37-45. doi: 10.1016 / j.jclinepi.2019.06.002. Disponível em: https://pubmed.ncbi.nlm.nih.gov/31195110/. Acesso em: 03 ago. 2019.

WORLD MEDICAL ASSOCIATION (WMA). Declaração de Helsinque da Associação Médica Mundial (WMA): princípios éticos para pesquisa médica envolvendo seres humanos. Finlândia: WMA, 1964. Disponível em: https://www.wma.net/wpcontent/uploads/2016/11/491535001395167888_DoHBrazilianPortugueseVersionRev.pdf. Acesso em: 21 jun. 2019.

YAZICI, Y; YAZICI, H. Informed consent: time for more transparency. Arthritis research \& therapy, [online], v. 12, n. 3, p. 121. Disponível em:

https://www.ncbi.nlm.nih.gov/pubmed/20537202. Acesso em: 27 jun. 2019 doi:10.1186/ar3004

Artigo submetido ao sistema de similaridade

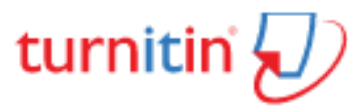

